Journal of Advanced Research in Fluid Mechanics and Thermal Sciences

\title{
Nozzle Type and Driving Speed Effects on Spray Density of Aerial Application According to the Wind Tunnel Measurements
}

\author{
Nasir Salim Hassen ${ }^{1,2,}{ }^{,}$, Nor Azwadi Che Sidik ${ }^{3}$ \\ Department of Thermo fluid, Faculty of Mechanical Engineering University Technology Malaysia, 81310 Skudai Johor, Malaysia \\ Agricultural Machinery Unit, Faculty of Agriculture, University of Diyala, Iraq \\ 3 Malaysia - Japan International Institute of Technology (MJIIT), University Technology Malaysia Kuala Lumpur, Jalan Sultan Yahya Petra (Jalan Semarak), \\ 54100 Kuala Lumpur, Malaysia
}

\section{ARTICLE INFO}

ABSTRACT

Article history:

Received 16 January 2021

Received in revised 20 May 2021

Accepted 25 May 2021

Available online 1 July 2021

\section{Keywords:}

Spray density; water sensitive papers; nozzle type; aerial application

\begin{abstract}
Spray density (Number of droplets $/ \mathrm{cm}^{2}$ ) is an important component of agricultural spraying processes. In the field, assessment of the spray density under effect of a number of variables such as nozzle type and driving speed without take in account the effect of cross wind speed is insufficient. In this study, to simulate field spray operation, tests were carried out in wind tunnel using automatic spraying mechanism to investigate and to clarify effect of three types of flat fan nozzles spray at three driving speeds under effect three cross wind speeds on spray density. Water sensitive papers (WSPs) were used to collect spray density data. The spray density was calculated through image processing program software. Performance of the spray nozzles was validated relative to experimental data of a TP11003 reference nozzle. Results indicated that XR11003 nozzle behavior was to some extent similar to that TP11003 nozzle under effect slow wind speed. It is also noticed that the spray density value decreased with increasing driving speed and wind speed. The highest spray density value was with driving speed of $2.2 \mathrm{~m} / \mathrm{s}$ and wind speed of $1 \mathrm{~m} / \mathrm{s}$, reaching 64.3 droplet $/ \mathrm{cm}^{2}$, while the spray density value with driving speed of $5.5 \mathrm{~m} / \mathrm{s}$ and wind speed of $3 \mathrm{~m} / \mathrm{s}$ was the lowest, reaching 3.8 droplet $/ \mathrm{cm}^{2}$. The current study presents that the use of DG11003 nozzle gives the best control of spray density data under effect very windy conditions to the reference nozzle.
\end{abstract}

\section{Introduction}

Agricultural production methods require spraying of pesticides to control insects, weeds and diseases to reduce yield losses and to improve the product quality [1]. Influence of agrochemical in the field depends on the main parameter is spray density. To control the targeted small size organisms requires coverage parts of the plant. Uniformity of spray distribution and density above the plants is one of the requirements of the successful spraying [2].

Spray density can be defined as number of droplets per unit area [3]. Spraying processes face a lot of challenges and problems because of overlapping various technical factors of the spraying

\footnotetext{
* Corresponding author.

E-mail address: nasirsalimhassen@gmail.com
}

https://doi.org/10.37934/arfmts.84.1.101110 
system with environmental condition variables and their interactions. Different types of nozzle tips were used to produce proper droplet size to reduce the volume of driftable droplets found in spray spectrums $[4,5]$. Spray nozzles are used in the field under effect numerous operation conditions such as driving speed and wind speed variations.

In aerial application, Speed of helicopter has a very significant impact on the spray deposition [6], and there is an important correlation between a spray drift potential index from the nozzle and the driving speed [7-9]. Spraying at a high driving speed increases a percentage of the fine droplets because of shattering the droplets [10-12] and increases the airborne spray drift [13].

Cross wind speed is a critical variable affects spray density, in which, it is not recommended to use aerial spraying systems in case of a high wind speed [14]. However, drift of spray droplets out of the target increases in windy spraying conditions [15] because the small droplets have no resistance to the strong air flow [16]. It is broadly agreed that spraying at a high driving speeds in potentially windy conditions support the small size droplets to drift escaping out of targeted crops or areas $[16,17]$.

The use of optimal droplet spectra improves the spray density. Droplet size included DV0.1, DV0.5 and DV0.9 is affected by the nozzle type according to the droplet spectra classification DSC $[18,19]$. Optimum performance of a spraying technique depends on achieving the most appropriate spraying parameters according to the standard protocols. However, it is motivating to note that there is no study about effect of triple interaction of nozzle type, driving speed and wind speed on the spray density in aerial application.

In order to improve the performance of spray system, the major objective of this study is to determine the effect of operation variables on the spray density .

\section{Materials and Methods}

It is important to use a wind tunnel to simulate and to investigate a number of variables in spraying process with a high degree of reliability because all variables can be changed freely [20-22].

\subsection{Automatic Nozzle and Nozzle Tips Selection}

To control opening and closing the spraying process inside the wind tunnel completely, an AA250AUH automatic nozzle was used as a fast response electro-hydraulic valve [23] with three types of flat fan spray nozzle tips (Drift Guard DG11003, Extended Range XR11003 and TeeJet TP11003 (reference nozzle) from spraying system Co. USA). These tips are the most common in agricultural spraying applications. The flow rate and spray pattern width for a single nozzle were adjusted [24]. Specifications of the selected nozzle tips are shown in Table 1.

Table 1

Specifications of the selected nozzle tips

\begin{tabular}{lllll}
\hline Nozzle & Nozzle Code & Working Pressure (bar) & Flow Rate (L/min) & Spray Pattern Width (m) \\
\hline TeeJet & TP11003 & 3 & 1.18 & 1.43 \\
Extended range & XR11003 & 3 & 1.18 & 1.91 \\
Drift guard & DG11003 & 3 & 1.18 & 1.90 \\
\hline
\end{tabular}




\subsection{DSC Measurements}

DSC measurements for the selected nozzle tips included DV0.1, DV0.5 and DV0.9. The nozzle tip was put at $0.50 \mathrm{~m}$ above the measuring point of the Phase Doppler Interferometer (PDI). Spray process was at a pressure of 3 bar. The weather conditions were $21^{\circ} \mathrm{C}$ and $69 \%$ a temperature and a relative humidity respectively according to the ASAE S-572 spray nozzle classification standard $[25,26]$.

\subsection{Dynamic Spray Distribution and Density Measurement}

Figure 1 shows experimental setup to evaluate spray distribution and density for different nozzle types in a wind tunnel at UTM Malaysia built according to ISO/DIS 22856-1 [27], using two dimensional spraying mechanism for simulating movements of the single nozzle in the established field conditions [28]. Specifications of the spraying mechanism are shown in Table 2. Two experiments were carried out to compare the effect of nozzle type, driving speed (DS) and cross wind speed (WS) on spray density as shown in Table 3.

Nozzle height above the wind tunnel ground was set at $0.50 \mathrm{~m}$. All the tests were carried out at a working pressure of 3 bar. Water sensitive papers (WSPs) were used as artificial collections [2] for spray distribution and density data [29]. WSPs were placed horizontally at row in the centre of the wind tunnel in five positions, the distance between the two samples in the collecting line was $25 \mathrm{~cm}$ $[30,31]$. To avoid boundary layer effects, the WSPs samples were placed at height of $0.07 \mathrm{~m}$ on the ground of the wind tunnel. Figure 2 shows the wind tunnel sampling scheme. After each spray run, WSPs were left to dry and then collected. The tests were repeated three times. For calculating spray density, each WSP was put in a small plastic box to take to the laboratory. A stereo microscope with digital camera (Leica Microsystems Cambridge Ltd United Kingdom) was used for recording and magnification of the WSP samples electronically. The spray density was determined through image processing program [29], using MATLAB-programming software version 7.12. When there is overlapping spots of some WSP samples, the number of droplets was set manually [32-34]. To interpret the uniformity of spray distribution, the coefficient of variation C.V was calculated in the Eq. (1).

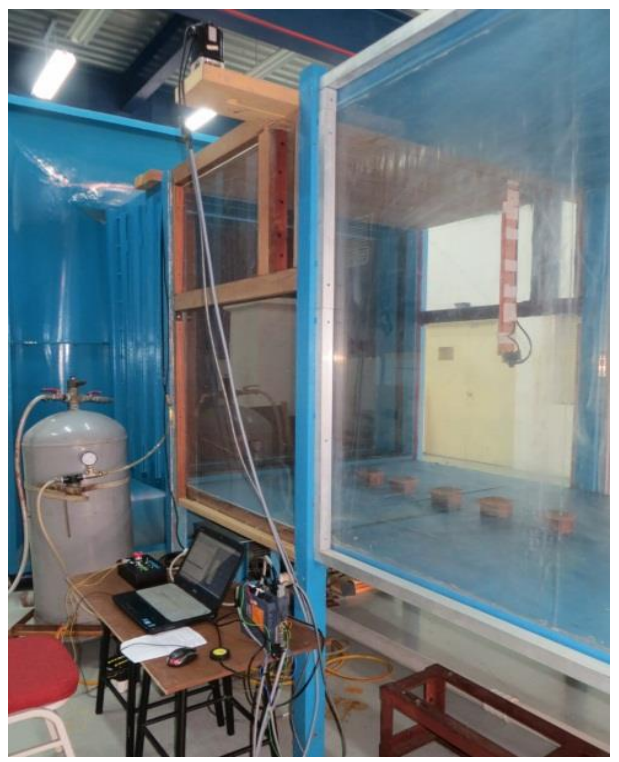

Fig. 1. Experimental set up for testing spray system in the wind tunnel 
Table 2

Specifications of the spraying mechanism

\begin{tabular}{ll}
\hline Parameter & Value \\
\hline Linear motion platform & \\
Model & SIMO series, PBC linear \\
Maximum speed & $6.2 \mathrm{~m} / \mathrm{s}$ \\
Motor and amplifier & \\
Servo motor & GYS - 751 D5 - HC 2 \\
Servo amplifier & RYT - 751 D5 - VV 2 \\
Maximum speed & 6000 rpm \\
spray nozzle & \\
Model & AA250AUH automatic spray nozzle \\
Valve type & Electrically-actuated hydraulic valve \\
Power & 24 VDC, 0.375 AMP \\
Nozzle tip sizes & Up to - 03 capacity \\
Maximum operating pressure & 7 bar \\
Maximum flow rate & 1.8 L/min \\
\hline
\end{tabular}

Table 3

Factorial experiments design

\begin{tabular}{lllll}
\hline Nozzle Code & Driving Speed $(\mathrm{m} / \mathrm{s})$ & Wind Speed $(\mathrm{m} / \mathrm{s})$ & & 3 \\
\hline DG11003 & 2.2 & 1 & 2 & 3 \\
XR11003 & 2.2 & 1 & 2 & 3 \\
& 2.2 & 1 & 2 & 3 \\
TP11003 $^{*}$ & 3.3 & 1 & 2 & 3 \\
& 4.4 & 1 & 2 & 3 \\
\hline
\end{tabular}

* TeeJet ISO standard flat fan nozzle is the reference nozzle

$C . V .=\frac{\sigma}{\bar{X}} \times 100$

where, $C . V=$ Coefficient of variation (\%), $\sigma=$ Standard deviation, $X=$ Average

$$
\begin{aligned}
& \sigma=\sqrt{\frac{1}{N-1} \sum(X-\bar{X})^{2}} \\
& \bar{X}=\frac{\sum X}{N}
\end{aligned}
$$

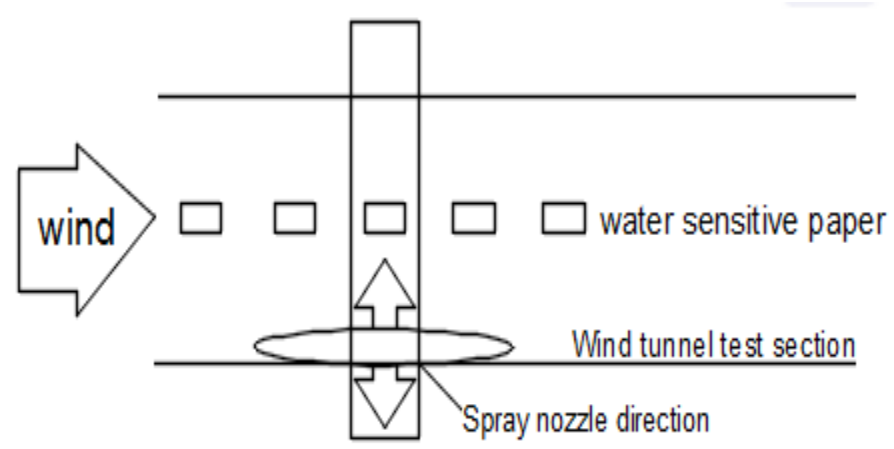

Fig. 2. Experimental layout of placement of water sensitive papers at target area and the direction of the nozzle movement in the wind tunnel 


\section{Results and Discussion}

\subsection{The DSC}

Table 4 shows the test results of DSC include DV0.1, DV0.5, and DV0.9 produced by the tested nozzles. It is very clear that nozzle type affects the droplet size. The DG11003 nozzle was achieved the highest value of the droplet size DV0.5 in comparison to the other nozzles.

Table 4

The DSC values for different nozzles

\begin{tabular}{llll}
\hline Nozzle Code & $\mathrm{DV}_{0.1}(\mu \mathrm{m})$ & $\mathrm{DV}_{0.5}(\mu \mathrm{m})$ & $\mathrm{DV}_{0.9}(\mu \mathrm{m})$ \\
\hline DG11003 & 159.7 & 300.9 & 397.1 \\
XR11003 & 138.1 & 262.5 & 382.5 \\
TP11003 & 163.0 & 275.1 & 385.6 \\
\hline
\end{tabular}

\subsection{The CV}

According to the CV values in Table 5, the DG11003 nozzle and XR11003 nozzle presented better spray density uniformity as compared to the TP11003 reference nozzle at different wind speeds. The results of coefficient of variation also showed that the best uniformity of spray distribution was at low wind speed for all the test nozzles.

Table 5

The $\mathrm{CV}$ values for different nozzles at three wind speeds

\begin{tabular}{lllll}
\hline Nozzle Code & Driving Speed $(\mathrm{m} / \mathrm{s})$ & \multicolumn{3}{c}{ Wind Speed $(\mathrm{m} / \mathrm{s})$} \\
\cline { 3 - 5 } & & 1 & 2 & 3 \\
\hline DG11003 & 2.2 & 0.59 & 0.68 & 0.74 \\
XR11003 & 2.2 & 0.62 & 0.67 & 0.72 \\
TP11003 & 2.2 & 0.68 & 0.69 & 0.79 \\
\hline
\end{tabular}

\subsection{Nozzle Type Effect on Spray Density}

Figure 3 shows spray density distribution for three types of nozzles. In Figure 3(a), when the wind speed is $1 \mathrm{~m} / \mathrm{s}$, there is similarity between TP11003 reference nozzle and XR11003 nozzle in spray density on the targeted areas under the nozzle, while increasing the wind speed to become $2 \mathrm{~m} / \mathrm{s}$ affected on spray density of the XR11003 nozzle and the number of droplets decreased more in comparison to the TP11003 reference nozzle as shown in Figure 3(b). At a high wind speed of 3m/s, it was noticed that the spray density of the XR11003 nozzle decreased a lot in comparison to the two nozzles TP11003 and DG11003 because of a high drift of its small droplets as shown in Figure 3(c).

In general, Figure 4 shows the relationship between wind speed and spray density for three nozzles. DG11003 nozzle achieved the best control spray density under effect of a high wind speed. 


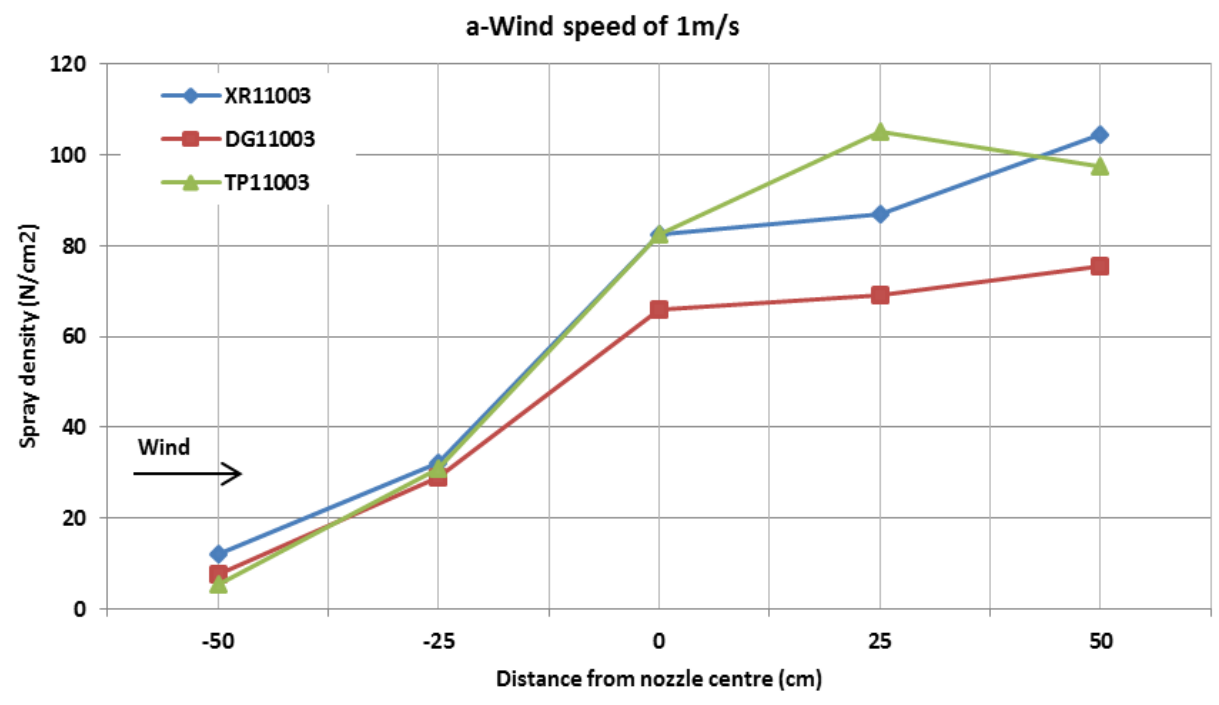

(a)

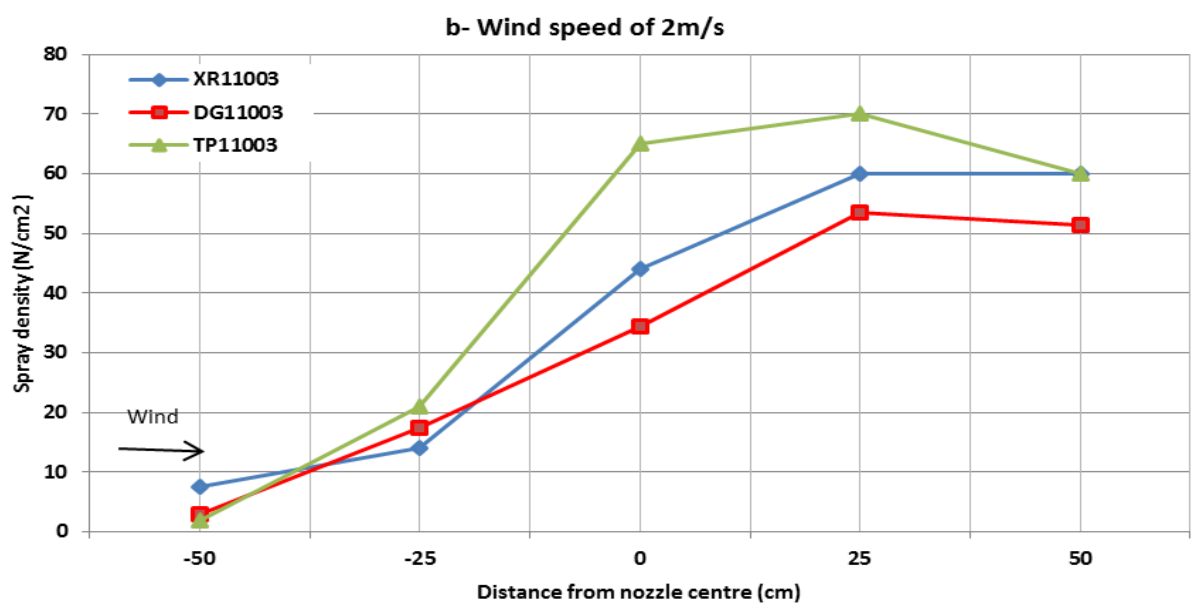

(b)

c- Wind speed of $3 \mathrm{~m} / \mathrm{s}$

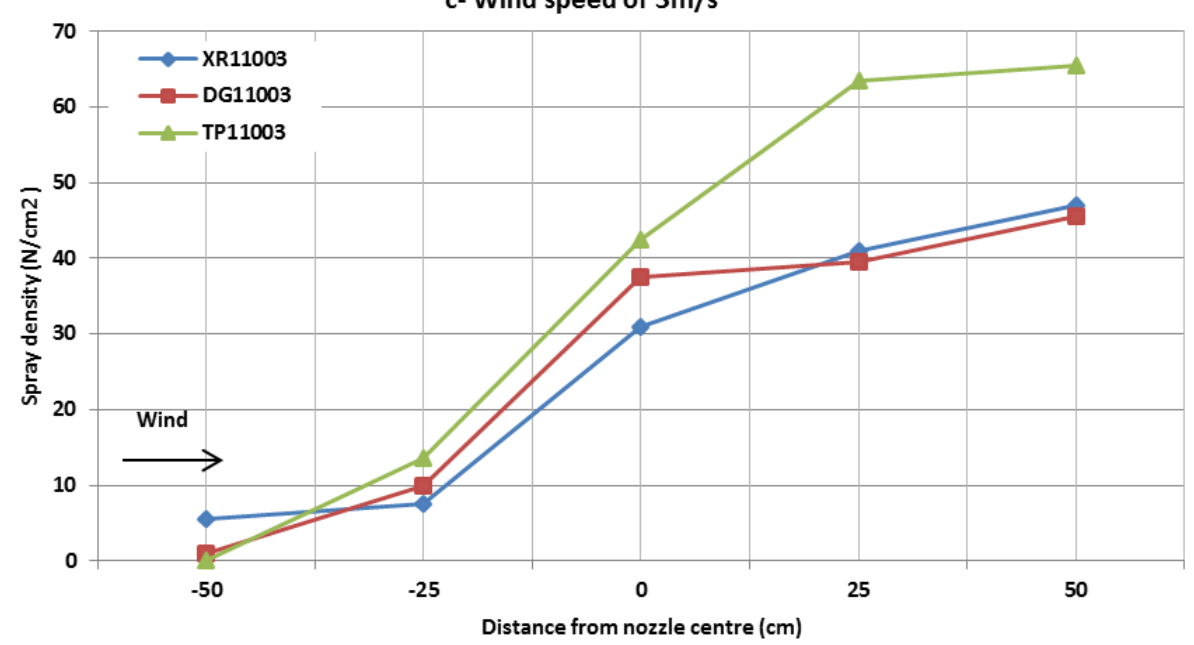

(c)

Fig. 3. Spray density for different nozzle types at driving speed of $2.2 \mathrm{~m} / \mathrm{s}$ and wind speeds; (a) $1 \mathrm{~m} / \mathrm{s}$, (b) $2 \mathrm{~m} / \mathrm{s}$, (c) $3 \mathrm{~m} / \mathrm{s}$ 


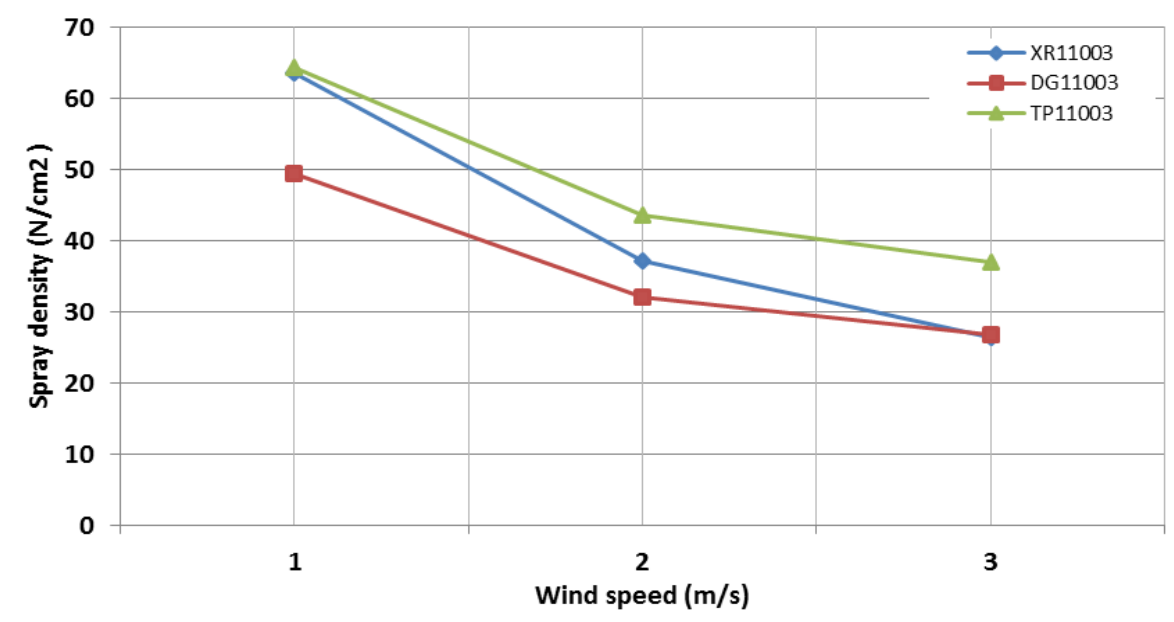

Fig. 4. Spray density for different nozzles at different wind speeds and at driving speed $2.2 \mathrm{~m} / \mathrm{s}$

\subsection{Driving Speed and Wind Speed Effects on Spray Density}

Figure 5 shows results of the effect of driving speed on spray density for TP11003 nozzle, it is clear that the spray density decreases at a higher driving speed along the working width of the spray nozzle compared to slower driving speed because of shattering the droplets and increase the number of drift-able droplets. In addition, spray time is reduced at high driving speed. Results of the test experiments of the effect of wind speed on TP11003 nozzle are provided in Figure 6. The spray density on the two sides of the nozzle decreases with increasing of wind speed.

To determine the effect of driving speed and wind speed interaction on spray density, the relationship between driving speed and spray density at three wind speeds was studied. Spraying application during windy conditions of $3 \mathrm{~m} / \mathrm{s}$ decreased spray density under the nozzles because of increasing the spray drift. In general, spraying at slow driving speed under effect of the slow cross wind speed had better spray density, but in the same time, reducing the driving speed during spraying operation would cause to the excessive use of agrochemicals as shown in Figure 7.

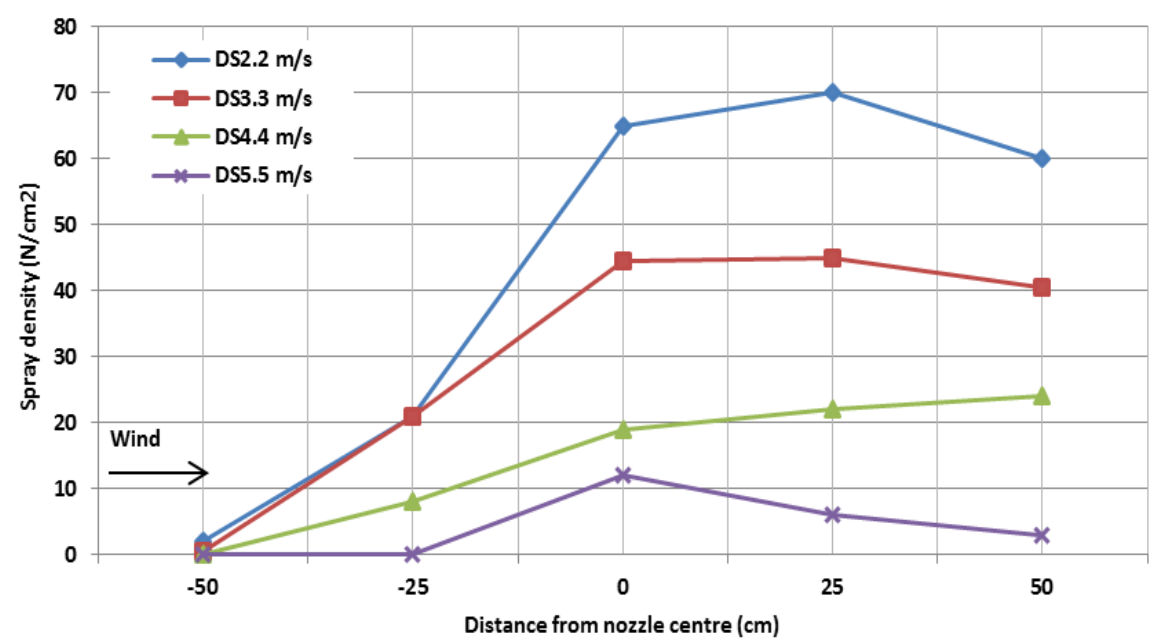

Fig. 5. Spray density for TP11003 nozzle at different driving speeds and at wind speed of $2 \mathrm{~m} / \mathrm{s}$ 


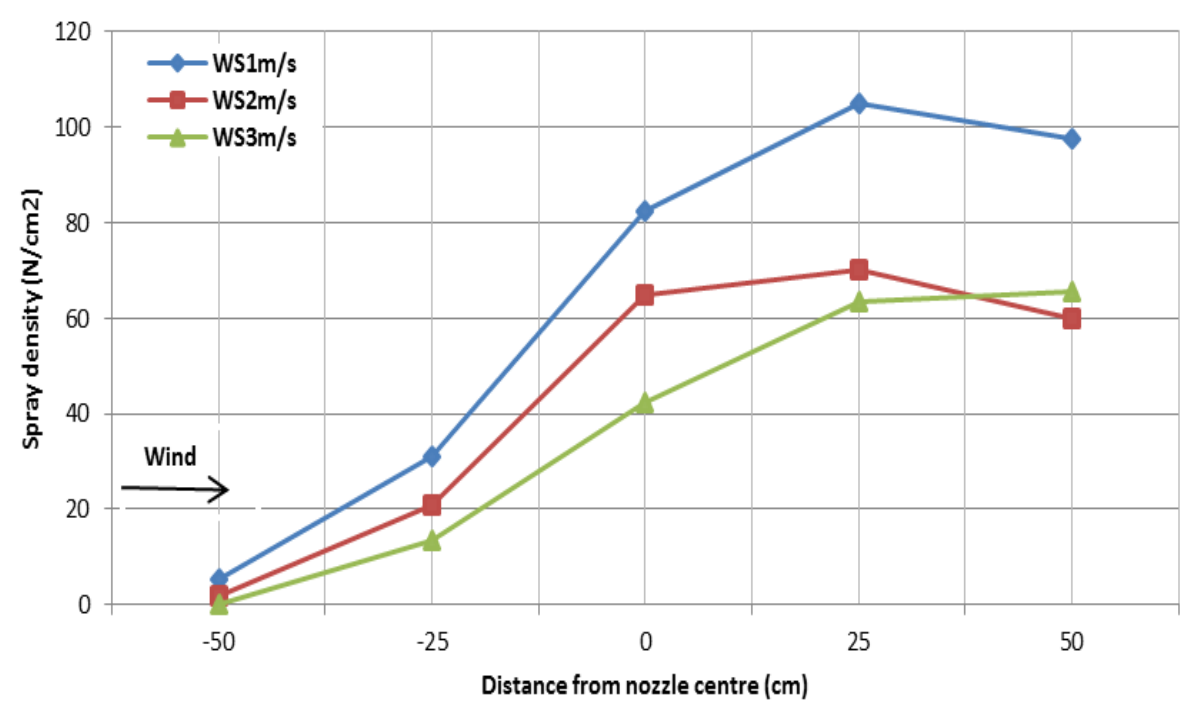

Fig. 6. Spray density for TP11003 nozzle at driving speed of $2.2 \mathrm{~m} / \mathrm{s}$ and at different wind speeds

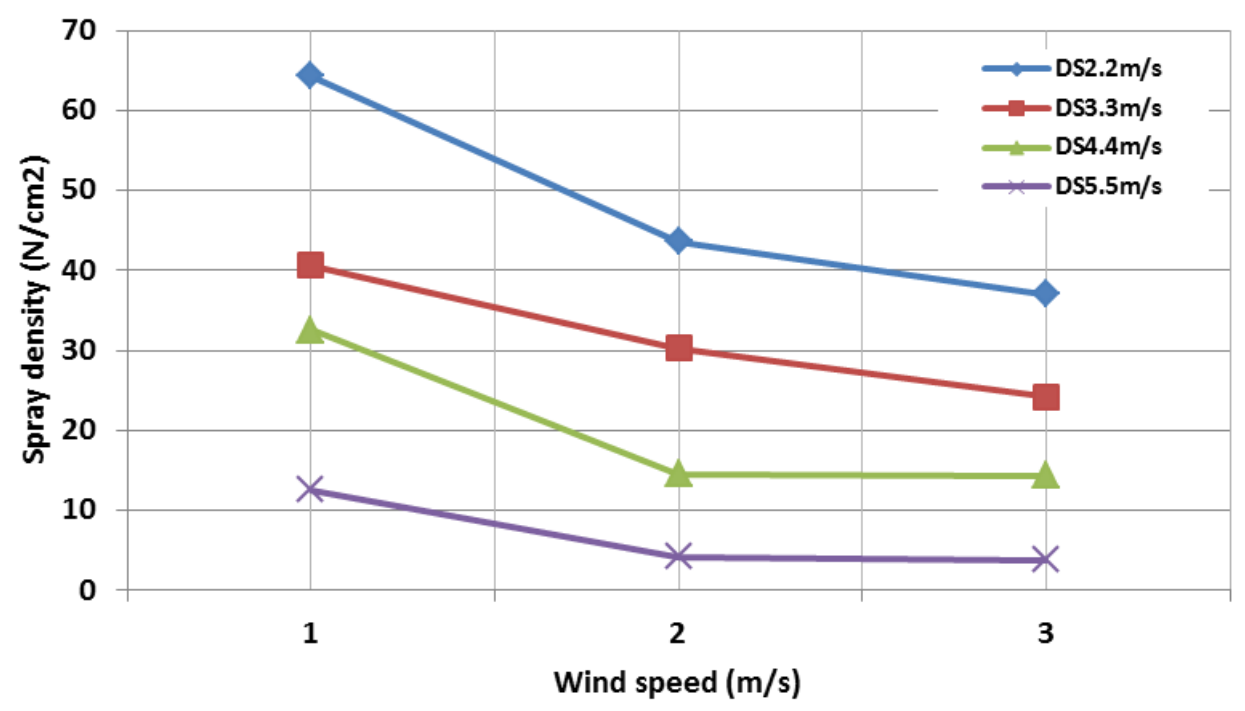

Fig. 7. Spray density for TP11003 nozzle at different wind speed and driving speeds

\section{Conclusions}

This study has demonstrated the most influential factors on spray density are nozzle type, driving speed and wind speed for aerial application. Characterization of the spray density in a wind tunnel leads to suggestions and recommendations for operators. Various droplet sizes and spray densities can be generated according to the nozzle type and driving speed. For this purpose, the laboratory experiments have focused on quantifying the droplet size for different nozzles. Choosing the proper driving speed should be considered during spraying operations to achieve better spray density. Management and reducing the spray drift can be done when use DG11003 nozzle at low wind speed and gives excellent coverage at driving speed $2.2 \mathrm{~m} / \mathrm{s}$. The CV and spray density values of DG11003 nozzle over a wide wind speed range indicated best spray uniformity to the rest nozzles making it ideal for use with aerial application. 


\section{Acknowledgement}

The authors would like to thank members of the aeronautics laboratory of the faculty of mechanical engineering, university technology, Malaysia.

\section{References}

[1] Norhidayah, M., A. Shaaban, M. F. Dimin, M. Y. Norazlina, and O. Rostam. "Optimization of Biodegradable Urea Production Process to Minimize Ammonia Release through Response Surface Method Experimental Design." Journal of Advanced Research in Applied Sciences and Engineering Technology 2, no. 1 (2016): 9-18.

[2] Hołownicki, Ryszard, Grzegorz Doruchowski, Waldemar Świechowski, and Peter Jaeken. "Methods of evaluation of spray deposit and coverage on artificial targets." Electronic Journal of Polish Agriculture Universities 5, no. 1 (2002).

[3] Hou, Chaojun, Yu Tang, Shaoming Luo, Jintian Lin, Yong He, Jiajun Zhuang, and Weifeng Huang. "Optimization of control parameters of droplet density in citrus trees using UAVs and the Taguchi method." International Journal of Agricultural and Biological Engineering 12, no. 4 (2019): 1-9. https://doi.org/10.25165/i.ijabe.20191204.4139

[4] R. Wolf. "Equipment to reduce spray drift." Kansas State University Agricultural Experiment Station and Cooperative Extension Service Publication\# MF-2445 (2000).

[5] Hoffmann, Wesley, Bradley Fritz, Jonathan Thornburg, William Bagley, Norman Birchfield, and Jay Ellenberger. "Spray drift reduction evaluations of spray nozzles using a standardized testing protocol." In Pesticide Formulations and Delivery Systems, 30th Volume: Regulations and Innovation. ASTM International, 2011. https://doi.org/10.1520/STP152720120017

[6] Qiu, Baijing, Liwei Wang, Donglin Cai, Jianhao Wu, Guorong Ding, and Xianping Guan. "Effects of flight altitude and speed of unmanned helicopter on spray deposition uniform." Transactions of the Chinese Society of Agricultural Engineering 29, no. 24 (2013): 25-32.

[7] Vanella, Giuseppe, Masoud Salyani, Paolo Balsari, Stephen H. Futch, and Roy D. Sweeb. "A method for assessing drift potential of a citrus herbicide applicator." HortTechnology 21, no. 6 (2011): 745-751. https://doi.org/10.21273/HORTTECH.21.6.745

[8] Van de Zande, J. C., H. Stallinga, J. M. G. P. Michielsen, and P. Van Velde. "Effect of sprayer speed on spray drift." Annual Review of Agricultural Engineering 4, no. 1 (2005): 129-142.

[9] De Schampheleire, Mieke, K. Baetens, D. Nuyttens, and Pieter Spanoghe. "Spray drift measurements to evaluate the Belgian drift mitigation measures in field crops." Crop Protection 27, no. 3-5 (2008): 577-589. https://doi.org/10.1016/j.cropro.2007.08.017

[10] Akesson, N. B., and W. E. Yates. "Pesticide deposit and activity as a function of spray atomizers and liquid formulation." In Agricultural engineering: Proceedings of the eleventh International Congress on Agricultural Engineering, Dublin, pp. 2081-2090. 1989.

[11] Kirk, Iva W. "Measurement and prediction of helicopter spray nozzle atomization." Transactions of the ASAE 45, no. 1 (2002): 27. https://doi.org/10.13031/2013.7866

[12] Barbosa, R. "Equipment Setup for Aerial Application of Liquid Pesticides." LSU, ag center, Department of Biological and Agricultural Engineering (2010).

[13] Miller, P. C. H., and R. W. Smith. "The effects of forward speed on the drift from boom sprayers." In Proceedings, Brighton Crop Protection Conference-Weeds, pp. 399-406. 1997.

[14] Hussain, Saddam, M. Jehanzeb Masud Cheema, M. Arshad, Ashfaq Ahmad, M. Ahsan Latif, Shaharyar Ashraf, and Shoaib Ahmad. "Spray uniformity testing of unmanned aerial spraying system for precise agro-chemical applications." Pakistan Journal of Agricultural Sciences 56, no. 4 (2019).

[15] Chen, Yayong, Chaojun Hou, Yu Tang, Jiajun Zhuang, Jintian Lin, and Shaoming Luo. "An effective spray driftreducing method for a plant-protection unmanned aerial vehicle." International Journal of Agricultural and Biological Engineering 12, no. 5 (2019): 14-20. https://doi.org/10.25165/i.ijabe.20191205.4289

[16] JCR, HUNT. "Spray jets in a cross-flow." Journal of Fluid Mechanics 365 (1998): 109-136. https://doi.org/10.1017/S0022112098001190

[17] Phillips, Jeremy Charles. "Agricultural spray droplet dispersion in turbulent windflow." PhD diss., University of Birmingham, 1998.

[18] Lodwik, Dariusz, Jerzy Pietrzyk, and Włodzimierz Malesa. "Analysis of volume distribution and evaluation of the spraying spectrum in terms of spraying quality." Applied Sciences 10, no. 7 (2020): 2395. https://doi.org/10.3390/app10072395

[19] Bache, D. H., T. J. Lawson, and S. Uk. "Development of a criterion for defining spray drift." Atmospheric Environment (1967) 22, no. 1 (1988): 131-135. https://doi.org/10.1016/0004-6981(88)90305-8 
[20] Murphy, S. D., P. C. H. Miller, and C. S. Parkin. "The effect of boom section and nozzle configuration on the risk of spray drift." Journal of agricultural engineering research 75, no. 2 (2000): $127-137$. https://doi.org/10.1006/jaer.1999.0491

[21] Walklate, P. J., P. C. H. Miller, and A. J. Gilbert. "Drift classification of boom sprayers based on single nozzle measurements in a wind tunnel." Aspects of applied Biology 57 (2000): 49-56.

[22] Parkin, C. S., and P. N. Wheeler. "Influence of spray induced vortices on the movement of drops in wind tunnels." Journal of Agricultural Engineering Research 63, no. 1 (1996): 35-44. https://doi.org/10.1006/jaer.1996.0005

[23] Moltó, E., B. Martín, and A. Gutiérrez. "Pm-Power and machinery: Design and testing of an automatic machine for spraying at a constant distance from the tree canopy." Journal of agricultural engineering research 77, no. 4 (2000): 379-384. https://doi.org/10.1006/jaer.2000.0621

[24] Guler, H., Heping Zhu, H. Erdal Ozkan, R. C. Derksen, Y. Yu, and C. R. Krause. "Spray characteristics and drift reduction potential with air induction and conventional flat-fan nozzles." Transactions of the ASABE 50, no. 3 (2007): 745-754. https://doi.org/10.13031/2013.23129

[25] Nuyttens, David, Katrijn Baetens, Mieke De Schampheleire, and B. Sonck. "Effect of nozzle type, size and pressure on spray droplet characteristics." Biosystems engineering 97, no. $3 \quad$ (2007): 333-345. https://doi.org/10.1016/i.biosystemseng.2007.03.001

[26] Womac, A. R. "Quality control of standardized reference spray nozzles." Transactions of the ASAE 43, no. 1 (2000): 47. https://doi.org/10.13031/2013.2686

[27] Stainier, C., M-F. Destain, Bruno Schiffers, and Frédéric Lebeau. "Droplet size spectra and drift effect of two phenmedipham formulations and four adjuvants mixtures." Crop protection 25, no. 12 (2006): 1238-1243. https://doi.org/10.1016/i.cropro.2006.03.006

[28] Hassen, Nasir Salim, and Nor Azwadi Che Sidik. "Wind tunnel measurements on the effect of sprayer speed on the droplet size spectra." Journal of Advanced Research in Fluid Mechanics and Thermal Sciences 43, no. 1 (2018): 104111.

[29] Marçal, A. R. S., and M. Cunha. "Image processing of artificial targets for automatic evaluation of spray quality." Transactions of the ASABE 51, no. 3 (2008): 811-821. https://doi.org/10.13031/2013.24519

[30] Fritz, B. K., Christopher Parker, J. D. López Jr, W. C. Hoffmann, and Paul Schleider. "Deposition and droplet sizing characterization of a laboratory spray table." Applied engineering in agriculture 25, no. 2 (2009): 175-180. https://doi.org/10.13031/2013.26326

[31] Hoffmann, W. Clint, A. J. Hewitt, J. A. S. Barber, I. W. Kirk, and J. R. Brown. "Field swath and drift analyses techniques." Paper Number: AA03-007 (2003).

[32] Hočevar, M., B. Širok, V. Jejčič, T. Godeša, M. Lešnika, and D. Stajnko. "Design and testing of an automated system for targeted spraying in orchards." Journal of Plant Diseases and Protection 117, no. 2 (2010): 71-79. https://doi.org/10.1007/BF03356338

[33] Sayinci, B., S. Bastaban, and HERMOSILLA J. SANCHEZ. "Determination of optimal spot roundness variation interval for droplet size analysis on water sensitive paper." Journal Of Agricultural Science And Technology 14, no. 2 (2012): 285-298.

[34] Fox, Robert D., R. C. Derksen, J. A. Cooper, C. R. Krause, and H. E. Ozkan. "Visual and image system measurement of spray deposits using water-sensitive paper." Applied engineering in agriculture 19, no. 5 (2003): 549. https://doi.org/10.13031/2013.15315 